\title{
Nasal Conditioning of Inspired Air, Innate Immunity in the Respiratory Tract and SARS-COV-2 Infectivity
}

\author{
Ranjan Ramasamy \\ ID-FISH Technology Inc. \\ 556 Gibraltar Drive, Milpitas, CA 95035, USA \\ Email: rramasamy@idfishtechnology.com
}

\begin{abstract}
A new hypothesis that the warming and humidifying (conditioning) of inspired air in the nasal cavity influences susceptibility to SARS-COV-2 infection, and thereby pathology, is proposed. This hypothesis is consistent with existing observations and amenable to experimental verification.
\end{abstract}

Key words: airway immunity; COVID 19; ethnic and age susceptibility to SARS-COV2; inspired air temperature; nasal function; respiratory tract; SARS-COV-2.

\section{Background}

Many factors that influence the infectivity of SARS-COV-2 causing the present serious pandemic remain to be clarified. Influenza and respiratory syncytial virus infections increase during winter in the temperate zone, and this has been widely attributed to greater survival of the virus in the cooler winter environment and more opportunities for transmission indoors [1]. Numerous outbreaks SARS-COV-2 disease in meat processing plants, which normally maintain low ambient temperatures, have been observed in several countries. Recent data show that the rates of exponential spread of SARS-COV-2 have a significant negative correlation with environmental temperature [2]. There are also ethnic variations in susceptibility to SARS-COV-2 disease and these have been attributed in part to differences in socio-economic and health status [3, 4]. Additionally, SARS-COV-2 disease generally becomes more severe with increasing age and this has been attributed to the age-related decline in immunity.

\section{Development of the hypothesis}

The nasal cavity has an important function in warming and humidifying (conditioning) inspired air before it enters the nasopharynx and trachea $[5,6]$. A rhinovirus that causes common cold replicated better at $33^{\circ} \mathrm{C}$ than $37^{\circ} \mathrm{C}$ in airway epithelial cells, and this was associated with the better pattern recognition receptor 
(PRR)-mediated induction of Types 1 and 3 interferons and attendant interferon stimulated genes (ISGs) by the virus at $37^{\circ} \mathrm{C}$ [7]. There is evidence emerging now to suggest that SARS-COV-2 also replicates better at $33^{\circ} \mathrm{C}$ than $37^{\circ} \mathrm{C}$ in airway epithelial cells and that this can also be attributed to earlier and more robust PRR-mediated induction of Type 1 and 3 interferons and ISGs at $37^{\circ} \mathrm{C}$ [8]. Nasal structures vary geographically, and this variation has been correlated with the differing needs to humidify and warm inspired air in cold and dry climates on the one hand and warm and humid climates on the other [9]. Intranasal air temperature and humidity were lower in an elderly group (mean age of 70y) compared to a young group (mean age of $27 \mathrm{y}$ ) and this was associated with larger nasal cavities due to atrophy of the nasal mucosa in the elderly group [10].

\section{Hypothesis}

I propose that at cold temperatures, e.g. during winter and in meat processing plants, inspired air is less efficiently warmed in the nasal cavity before entering the nasopharynx and trachea. This can make innate immune responses to SARS-COV-2 virus less effective in epithelial cells of the upper respiratory tract, permitting more robust viral replication. Greater viral replication in this manner can then be expected to lead to spread of the virus to the lungs, greater pathology and increased viral shedding.

\section{Implications of the hypothesis}

The importance of nasal conditioning of inspired air is a poorly explored factor in SARS-COV-2 infectivity and better understanding of it may lead to the development of more effective measures to reduce infections and control the pandemic. The hypothesis predicts that simple measures like minimizing exposure to cold air and covering the nose with a scarf may help the nasal cavity warm inspired air more efficiently, thereby reducing infections through more effective early immune responses. The hypothesis also implies that variations in nasal conditioning of inspired air can contribute to ethnic and agerelated differences in susceptibility to infection with SARS-COV-2. Many of these predicted outcomes can be experimentally tested.

\section{References}

[1] S. Paynter. Humidity and respiratory virus transmission in tropical and temperate settings. Epidemiol. Infect. 143 (2015) 1110-1118. 
[2] G. Livadiotis. Statistical analysis of the impact of environmental temperature on the exponential growth rate of cases infected by COVID-19. PLoS. ONE 15 (2020) e0233875. https://doi.org/10.1371/journal.pone.0233875.

[3] Public Health England. Beyond the data: Understanding the impact of COVID-19 on BAME groups. June 2020.

[4] Centers for Disease Control and Prevention. COVID-19 in racial and ethnic minority groups. https://www.cdc.gov/coronavirus/2019-ncov/need-extra-precautions/racialethnic-minorities.html (Accessed 13 July 2020).

[5] S. Naftali, M. Rosenfeld, M. Wolf, D. Elad D. The air-conditioning capacity of the human nose. Ann. Biomed. Eng. 33 (2005) 545-553. PMID: 15909660

[6] T. Keck, J. Lindemann. Simulation and air-conditioning in the nose. Laryngorhinootologie 89 (2010) Supplement 1:S1-14. doi: 10.1055/s-0029-1246123.

[7] E.F. Foxman, J.A. Storer, M.E. Fitzgerald, B.R. Wasike, L. Hou, H. Zhao, et al. Temperature-dependent innate defense against the common cold virus limits viral replication at warm temperature in mouse airway cells. Proc. Natl. Acad. Sci. USA 112 (2015) 827-832 doi: 10.1073/pnas.1411030112

[8] P. V'kovski, M. Gultom, S. Steiner, J. Kelly, J. Russei, M. Mangeat, et al., Disparate temperature-dependent virus - host dynamics for SARS-CoV-2 and SARS-CoV in the human respiratory epithelium. bioRxiv (2020) preprint doi:

https://doi.org/10.1101/2020.04.27.062315.

[9] A.A. Zaidi, B.C. Mattern, P. Claes, B. McEvoy, C. Hughes, M.D. Shriver. Investigating the case of human nose shape and climate adaptation. PLoS Genetics 13(3) (2017) e1006616.

[10] J. Lindemann, D. Sannwald, K. Wiesmiller. Age-related changes in intranasal air conditioning in the elderly. Laryngoscope

118 (2008) 1472-1475 doi: 10.1097/MLG.0b013e3181758174. 